\title{
Lexical Chunks Formulaic Sequences and Yukuai: Study of Terms and Definitions of English Multiword Units
}

\author{
Ling Zhang ${ }^{1} \&$ Ping $\mathrm{Lu}^{1}$ \\ ${ }^{1}$ English Department, College of Foreign Languages, Zhejiang University of Finance and Economics, China \\ Correspondence: Ling Zhang, English Department, College of Foreign Languages, Zhejiang University of \\ Finance and Economics, Hangzhou, Zhejiang Province, China. E-mail: 1lzzbox@126.com
}

$\begin{aligned} & \text { Received: January 24, } 2017 \\ & \text { Accepted: February 10, } 2017 \quad \text { Online Published: February 15, } 2017 \\ & \text { doi:10.5539/ells.v7n1p74 }\end{aligned}$ URL: http://dx.doi.org/10.5539/ells.v7n1p74

\begin{abstract}
According to the theory of mental lexicon, lexical chunks refer to the multiword units with chunking effects while being processed in utterences. Language acquisition studies hold that formulaic sequences undertake more pragramatic functions bearing more conceptual processing and cultural information. There are some overlaps in the two terms. In the SLA studies in China, researchers attempted to use the coined term Cikuai to be the substitute of these two literally-translated terms - Cihui Zukuai for lexical chunks in Chinese and Chengshi Yu for formulaic sequences in Chinese. This paper proposes that lexical chunks and formulaic sequences have respective linguistic and cognitive features, which direct L1 and L2 speakers to process lexico-semantic multiword units in discourse in different ways. They are the subordinate terms of multiword units in English. This paper claims that the present terms can refer to holistically processed multiword units due to their formulaic and chunking effects. The significant differences lie in their degree of compositionality and semantic productivity. The lexical chunks have higher compositionality and semantic transparency, whereas the formulaic sequences are dynamic lexico-semantic multiword units, which offer exemplars instead of chunks for the reconstruction of lexical items in certain discourses. With regard to the lexical features of meaning extension, recursion and creativeness, we figure out their working definitions and come to the conlusion that Yukuai is not a good terminology to cover all the features entailed in them.
\end{abstract}

Keywords: lexical chunks, formulaic sequence, Yukuai; compositionality and semantic productivity, working definition

\section{Introduction}

Multiword unit generally refers to a string of collocated words, often concurrent and with relatively fixed lexical components and structures. The related studies, originated in western linguistics in the 1920s and 1930s, have been developed into the studies of phraseology and mental lexicon (Sinclair, 1991; Howarth, 1996; Cowie, 1998; Alison Wray, 2002; Wei, 2011 etc.). This study has so greatly aroused SLA researchers' unexpected interests that they have contributed many kinds of terminology for the multiword units in English due to their respective research methods and interpretations of the diversified lexical relations (Note 1). The psycholinguistic study has directed researcher's attention to the mental representations in multi-word unit processing since 1990s. And there have two core terms appeared frequently-lexical chunks and formulaic sequence, where the psychological terms chunk and formulaic show the obviously different stresses: in lexical chunks, "chunks" is the core word, while in formulaic sequence; "formulaic" is merely the modifier. This tells that researchers have studied the special linguistic phenomenon from the different perspectives; whereas it has brought some incidental terminology problems in the study of multi-word unit in China.

Since the study of multi-word unit has been introduced into English vocabulary acquisition in China, a critical question came to researchers is how to translate the various kinds of terms for Englsih multiword units into Chinese. At the very beginning in the 1990s, researchers made the translations in word-by-word translation, such as lexical chunk as Cihui Zukuai in Chinese and formulaic sequence as Chengshi Yu. Due to the vague definitions of lexical chunk and formulaic sequence, a new term Yukuai in Chinese became more popular as a substitute of Lexical chunk (Cihui Zukuai) and formulaic sequence (Chengshi Yu). Searching results in CNKI data bank reveal an annual average of 62.15 related articles published in the leading linguistic academic journals in China (2001-2015), 63.8 of which used the term Yukuai, 47.5 Cihui Zukuai and 8.5 Chengshi Yu (Note 2). 
The coined term Yukuai in Chinese seems to have bridged the gap between Lexical chunk (Cihui Zukuai) and formulaic sequence (Chengshi Yu). However, the fact is just opposite. Some new problems aroused in the use of Yukuai in second vocabulary acquisition.

The primary problem is Yukuai cannot merge the two terms-Lexical chunk (Cihui Zukuai) and formulaic sequence (Chengshi $\mathrm{Yu}$ ) into one. They are inherently different in linguistic features. It is easily to be confused by using Yukuai only to learn the nature of different kinds of multi-words in English. It is more likely to mislead researchers' full understanding of L2 lexical processing at both lexical and syntactic levels, and L2 learners' better understanding of their semantic compositionality and transparency in L2 discourse as well. The second problem is the term Yukuai is a coined disyllabic word in Chinese. Yu originally means a language or utterance as noun and speak as verb. In Chinese Yuhui is a conventional disyllabic word as a general term of words and phrases. Hui in Yuhui is the same word in Cihui Zukuai in Chinese orthography, which means a collection of word. We suppose that Yukuai is not an accurate equivalent term to Lexical chunk (Cihui Zukuai) and formulaic sequence (Chengshi Yu). Furthermore, there are more single words and fixed phrases than formulaic sequences in word lists for L2 vocabulary acquisition in English textbooks in China. This would confine learner's positive lexical input into one-side lexical knowledge. L2 learners may effectively memorize the basic meanings of certain words while at advanced English learning they may end up lacking in the input of lexical-semantic network, which may inhibits learners' theme-relevant cognition of related concepts (Zhao, 2011; Jiang, 2004; Han, 2004).

The problems above call for a theoretical study of what is Lexical chunk (Cihui Zukuai) and what is formulaic sequence (Chengshi Yu). This study aims to unveil the nature of Lexical chunk (Cihui Zukuai) and formulaic sequence (Chengshi $\mathrm{Yu}$ ) with regard to their semantic compositionality and their mental representation. The nature of lexeme and lemma, namely recursion, creativity and extension, will be further discussed. All the study will finally prove why Yukuai cannot substitute the present two terms lexical chunk and formulaic sequence. This paper consists of three parts besides Introduction and Conclusion. They are Literature Review, and theoretical studies of lexical chunk and formulaic sequence respectively.

\section{Literature Review}

Based on the studies of lexical processing in the aspects of multi-word unit compositionality, lexical access and retrieve, researchers both in psycholinguistics and SLA find the following consensus, that is, (1) there exists mental lexicon (Aitchison, 1994, 2010; Carroll, 1999); (2) the organization pattern of mental lexicon is one of the important dimensions in lexical competence assessment (Meara, 1996; Chapelle, 1998; Wolter, 2001; Jiang, 2007); (3) lexical chunks and formulaic sequence are the two major representations of mental lexicon (Nattinger \& DeCaricco, 1992; Sinclair, 1991; Lewis, 1993; Skehan, 1998; Wray, 2002; Nesselhauf, 2005; Jiang \& Nekrasova, 2007; Conklin\&Schmitt, 2008; Andrea, 2012; etc). What are highly controversial at present are the interlexical and intralexical organization of lexical chunks and formulaic sequences, and how they respectively help L2 learners get access to their lexical and conceptual meanings in bilingual processing.

\subsection{Studies on the Pattern of Mental Lexicon Organization}

Spreading Activation Model (Collins \& Loftus, 1969, 1975) is by now the most influential one in describing the organization and structure of mental lexicon. It stresses that semantic network consists of words and their semantic elements, lexicon is closely related to syntax and phonetics. On the other hand, it emphasizes the spreading and activation of concepts, claiming that the spreading and activation of the nodes depend on how close lexical semantics are associated with each other. To unfold the organization of mental lexicon, researchers, based on this model, used trichotomy to classify the ways lexical semantics are connected.There are three typical patterns, namely phonetics-syntagmatic-paradigmatic (Wolter, 2001; Namei, 2004; Nissen \& Henriksen, 2006); phonetic-semantic-syntax (McNeil, 1966; Zareva, 2005); form-based reaction-meaning-based reaction-location-based reaction (Fitzpatrick, 2006).

The major deficiency in this model is the lack of a deeper analysis to tell the relation between lexical type and conceptual model in lexical items as nodes in semantic network. This partly explains why category-specific nodes and standard terms become the problems in the current multiword unit research.

\subsection{Mental Lexicon Processing Model}

The research of mental lexicon processing has proved that chunks, formulaic sequences, etc., as multilevel constructs of meanings are set up in accordance with native speaker's cognitive experience and language knowledge. This is in line with the claim of usage-based cognitive semantic study. That is, humans more easily tend to acquire new knowledge (or information) related to given schema (Tyler, 2012, p. 6). Table 1 and Table 2 
summarize the results in the phases of pro- and post-mental lexicon processing respectively.

Table 1. L1 mental lexicon processing models and their characteristics

\begin{tabular}{ll}
\hline Logogen Model (Morton, 1982) & $\begin{array}{l}\text { 1. Words are processed through different channels. } \\
\text { 2. Lexicon and semantics are activated by the auditory, visual } \\
\text { elements and contextual information for the retrieval of words. }\end{array}$ \\
$\begin{array}{l}\text { 3. Mental lexicon processing can only become available when there } \\
\text { is a one-to-one correspondence between lexicons and semantic. }\end{array}$ \\
\hline Search Model (Foster, 1976; 1979) \\
$\begin{array}{l}\text { 1. Words are processed through different channels. } \\
\text { 2. Mental lexicon processing is automatic and orderly. }\end{array}$ \\
$\begin{array}{l}\text { 1. Words are processed through different channels. } \\
\text { 2. Mental lexicon processing deals with such properties as sound, } \\
\text { appearance, meaning and grammar. } \\
\text { 3. All the properties worked equally together on lexicon semantic } \\
\text { processing. }\end{array}$ \\
\hline
\end{tabular}

While the above models focused on the internal processing of mental lexicon, they ignored the role macro cognitive factors (such as discursive environment, encyclopedic knowledge) played in speech processing, and did not tell how to identify lexical processing unit and which is processed first the sequence. Before long Carroll (1999) proposed that factors like the appearance, pronunciation, meanings, related grammar, semantic and context will activate the representation of a lexical item in discourse; and the retrieval of mental lexicon is a process, in which lexical knowledge is activated and proliferated. Thus the focus of bilingual lexical processing shifted to cognitive control mechanism, and new findings were found in the inhibition and activation of target/non-target words or semantic meanings (Tokowicz, 2015). The details are displayed in Table 2.

Table 2. Bilingual mental lexicon processing models and their characteristics

\begin{tabular}{|c|c|}
\hline $\begin{array}{l}\text { The Inhibitory Control Model } \\
\text { (ICM; Green, 1998) }\end{array}$ & $\begin{array}{l}\text { 1. emphasizes the existence and function of inhibitory control } \\
\text { mechanism } \\
\text { 2. proposes a new concept beyond the lexicon-semantic } \\
\text { system : Language Task schema } \\
\text { 3. Inhibitory mechanism happens outside lexical semantic } \\
\text { system, and the control of activation level of the target word } \\
\text { can be realized through altering the activation level of lexical } \\
\text { representation within lexical semantic system. }\end{array}$ \\
\hline $\begin{array}{l}\text { Bilingual Interactive Activation Model (BIA) } \\
\text { (Van Heuven, Dijkstra, Grainger, 1998) }\end{array}$ & $\begin{array}{l}\text { 1. Bilingual information is represented in a single uniform of } \\
\text { mental lexicon. } \\
\text { 2. Language selection occurs within lexical system; control } \\
\text { elements function within mental lexicon. } \\
\text { 3. One-way/Bottom-up control of lexical information passing }\end{array}$ \\
\hline $\begin{array}{l}\text { 3. Bilingual Interactive Activation Plus Model } \\
\text { BIA+ (Dijikstra \& van Heuven, 2002, 2010) }\end{array}$ & $\begin{array}{l}\text { 1. adopts the concepts of task schema and control in ICM } \\
\text { 2. Two subsystems are identified: word identification } \\
\text { subsystem (language information processing) and } \\
\text { task/decision subsystem (non-language information } \\
\text { regulation); there is a simple one-way influence between the } \\
\text { two, with the former as the basis of the latter, and the latter } \\
\text { exerting no influence on the former. } \\
\text { 3. Language representation includes phonologic, semantic and } \\
\text { morphological ones; language nodes don't inhibit language } \\
\text { categories; up-bottom and self-activated lexical processing are } \\
\text { adopted. }\end{array}$ \\
\hline
\end{tabular}

ICM involves inhibitory control, and it assumes that only when the non-target lexical items are activated will inhibitory control does work for lexical processing, i.e., to accelerate the activation and consequently the retrieval of target lexicons. The higher level a language is activated, the more frequently inhibitory processing will be carried out. The main evidences for the existence of inhibitory control are familiarity-based stimulus, inhibitory disparity (or dissymmetry switching cost), and the cognitive energy to inhibit the activation of 
non-target language mainly includes task goal, schema and language structure proficiency. The two aspects of inhibition are schema and language tags in lexical semantic system, with the latter undertaking the dual-task of marking up language types and stimulating the language schema in cognitive task.

BIA Model and later a modified version - the BIA Plus Model were presented by scholars such as Grosjean (1998, 2008), Dijikstra \& van Heuven (2002), who paid more attention to word selection within lexical system. Unlike ICM, which focuses on how to eliminate the interference from non-target language, BIA/BIA Plus Model stresses language nodes and morphological representations, regards lexical identification as a stimulating mechanism, and suggests that bilingual processing follow the principle of equal opportunity. Due to various language levels, processing tasks, and degrees of closeness between two languages, etc., differences exist in different internal language processing mechanisms. In BIA Plus Model, the processing system consists of the two subsystems - task control and lexical cognition. Using stimulating words to test how much a language is stimulated, the results confirm that clear directions and closeness between the two languages in the task affect the cognitive degree of bilingual lexicon. SOPHIA Model (the Semantic, Orthographic, and Phonological Interactive Activation Model; van Heuven \& Dijkstra, 2001), its lexicon identification system, explains how a target word is stimulated through the joint work of semantic, morphological and phonological function of the word.

Developed from the previous studies, DST (Dynamic Systems Theory) of L2 contended that language ability is the result of the interaction of environment, behavior and (study) time; and the further studies have claimed that both target words and non-target words in the inhibitory-control mechanism and stimulating mechanism affect the lexical-semantic selection together in the bi-/multi-lingual lexical-semantic processing (de Bot, Lowie, \& Verspoor, 2005). But arguments still remain about the object of inhibition and stimulation in bilingual processing mental lexicon with regard to its abstractness and complexity, which partly result in the lack of a correct definition of the term "multiword unit" in English.

\section{Lexico-Semantic Features of Lexical Chunk in Terms of Its Compositionality, Creativity and Mental Representation}

As is discussed before, the storing and retrieving of mental lexicon is an orderly and semantic-based processing, and lexical meanings get accessed via family words. Based on the productivity, creativity of lexical chunks and the attributes of mental lexicon, this part discusses the categories of multiword units and their distinguishing features in terms of compositionality and semantic transparency of lexical item.

\subsection{Compositional Characteristics of Lexical Chunks and Its Creativity in Processing}

The notion of lexical chunk was initiated by J. Becker between 1970s and 1980s (Becker, 1975; Bolinger, 1976). With further studies on phrases, collocation and mental lexicon, it was gradually adopted by L2 lexical acquisition researchers and became the main index to measure the width and depth of L2 learners' lexical knowledge. Nation (1990) suggested that lexical collocation and semantic association network be included as the two major factors to assess L2 learners' proficiency level, while Nattinger \& DeCaricco (1992) hold that it is the number of lexical chunks stored in the brain of language learner that affect one's language proficiency. Lewis (1993) defines lexical chunk as "language consists of grammaticalized lexis" (ibid.), and "lexical approach", which give the greatest spur to the study of the nature and use of lexical chunks in the field of linguistics. Holistically processing of lexical chunks became the focal both in L2 vocabulary acquisition and psycholinguistics.

Lexical chunks are highly compositional and semantically transparent, which are evident in the following three aspects: (1) They are cross-layered structures (ranging from phonological, lexical semantic to pragmatic layer of language) made up of different numbers of words, like "I see/Are you sure/Why not" in English, and many double-syllable words in Chinese (Dong, 2011). Each lexical item in the above-mentioned sentences and phrases has its fixed form and location, clear pragmatic markers, and lexical structure is high in its ability to chunk and semantic transparency. (2) They are rich in lexico-semantic information, suitable to be processed in the sentence and semantic level. Take "task-based" as an example. The lexical chunk is made up of a concrete noun + based, which is the product of both English lexical grammar and lexical meaning. Hence lots of synthesized phrases like "theory-based", "study-based" follow the rule. (3) With rich semantic cues in lexical nodes, easy to be activated, and abundant in pragmatic functions, they are applicable in a wide range of contexts. Take "coffee table" as an example. In this lexical chunk, the combination of two concrete nouns implies a specific way to study and communicate. Its derivatives such as "Chinese table", "English table", where the extended semantic meaning of the core word "table" decide the meaning of the whole lexical chunk, tell clearly the free conversation drills in language learning. Compared with idioms/idiomatic phrases, which are highly culturally 
loaded, lexical chunks are slightly weaker in compositionality and semantic transparency, but enjoy similar use frequencies, and wider range of uses in different discourse domains, formal or informal. Thanks to their open structure, they allow for the flexible substitution of the word at the node when called for by varied discourse domains, and thus a relatively stronger productivity.

According to its pragmatic function and semantic transparency, lexical chunks show a continuum from fixed to semi-fixed compositionality. Take for example the three groups of English expressions below:

e.g., 1). I see/Are you sure/Why not/thanks/and you/What about/and things like that/Have a nice day/small world etc.

2). task-based/absent minded/earth quake/trouble maker/coffee table/book report etc.

3). see a doctor/demand and supply/student and teacher/time and tide/kill time/fish and chips/bread and milk etc.

Group 1 consists of sentences, phrases and words with salient pragmatic functions, high semantic transparency, and the best compositionality. They tend to show clear pragmatic functions and fixed semantic meanings when used in different discourse domains, and each element in lexical chunks is not substitutable (including liaison, weak form, rise-fall tone in phonological level; morpheme, synonym in the lexical level; tense, voice and person, etc., in the semantic level). In Group 2 are lexical chunks with less clear pragmatic functions but more significant grammatical and extended discourse meanings. These are the lexical chunks with stronger semantic motivation, excursiveness (shown in its creativeness), regenerative ability, and can serve as a construction. Newly-generated words or lexical chunks based on them usually have salient meanings and thus easy to understand and memorize. Sample lexical chunks in Group 3 are not as clear as those in Group 1 in terms of pragmatic function in discourse domain, and not as salient as those in Group 2 in terms of grammatical and extended discourse meanings, but they have clear semantic markers indicating a specific discourse domain.

The semantic compositionality discussed above is supported by many examples in Chinese disyllabic words and sentences with semantic markers. For example:

e.g., 1a. nín lăo gāo shòu a?

(How old are you?)

1b. quing yòng chá / qǔng màn zǒu

(Please take a cup of tea. / Please walk slowly, which means take care or bye-bye.)

1c. dà jiā hăo!

(Hello everyone!) (greetings to a group of people)

1d. nǐ shuō ne? / zěn me bàn?

(what do you think? / What should I do?) (asking for advice)

2. disyllabic words:

wén huà / jiào yù / diàn năo / yán sè / xiě zuò / shēng bìng / dă zì / zhuī găn / shēn qǔng

(culture / education / computer / color / writing essay / be ill / type letters / run after / apply for)

3a duān chá dào shuǐ

(serve drinks)

3b. dōng nán xī běi / nán nŭ lăo shào / shī shēng / zhuō yǐ / shàng xià zuǒ yòu / fáng qián wū hòu

(east and west, south and north / men and women, old and young / teacher and student / desk and chair / up and down, left and right / around the house)

3c. guō wăn piáo péng / chái mǐ yóu yán

(pots and pants / fuel, rice, oil and salt—daily necessities)

"gāo shou" in (1a) is used when ask about the age of an old person in Chinese, which shows respect to a senior person. In the diasyllabic word "gāo shou", the modifer "gāo" has metaphoric meaning which only plays the role of pragramtic cue for politeness and respect as well. The use of "gāo" derives from its original meaning "up/high" in source domain, which indicates the spatial position. The image schema entailed in "gāo" helps the mapping of original meaning into target domain and develops into its extended meanings such as "superior to", "respect". There are some similar disyllabic words like "gāo táng" (your respectable parents), ("gāo shǒu" (master hand), 
"gāo jiàn" (your brilliant idea). Moreover, "shòu" is the formal expression of "age". More disyllabic words were developed such as shòu chén (birthday of an elderly person) / cháng shòu (longevity) / shòu xīng (respectful address to an elderly person).

Examples in 1(b) have the pragmatic function of courtesy owing to the words "yòng" (eat or drink) and "màn" (slowly) in the tactful expressions. Similar expressions are such lexical chunks as "màn yòng (drink or eat slowly)", "yòng cān" (eat your meals) (which are double syllable words), and "qǔng liú bù." (which is a sentence).

All the four types of sentences in Group 1 are subject to the change of discourse domain, with strong compositionality, salient semantic markers, clear pragmatic functions and are not replaceable.

With the disyllabic words in Example 2, both high compositionality and creativeness, and each word in Group 3 stalled in a basically fixed position. They are collocational links with high frequency and compositionality, and the conceptual model with characteristics of discourse communities become more prominent due to the word order in phrases and sentences. The change of a certain word in a phrase won't change its meaning as a whole, but people just won't simply accept this kind of sequential change. Take $3 \mathrm{a}$ as example. This phrase contains two verbial phrases: "duān chá" (serve the tea) and "dào shuı̌" (pour the water). The common sense in China is a cup of tea won't be made until tea leaves are soaked for a while in warm water, and naturally we are supposed to "pour the water first, and serve the tea later", hence "dào shuǐduān chá", which turned out to be not the case at all. Influenced by the habitual expressions from the discourse community, people tend to use "duān chá dào shuî", not the other way around. The contractual motivation of phrases in $3 \mathrm{~b}$ and $3 \mathrm{c}$ are in the light of image schema, like the "path (first/start-later/end) schema" and "position (up-down, in front-behind) schema" followed by phrases in $3 b$. For instance, "daybreak" is regarded as the beginning of a day, so is taken as "early" (zăo). In the northern hemisphere, the sun usually shed its first light over the earth in the east (dōng) and south (nán) in stead of west (xī) and north (běi), and that's why the directions of dōng and nán are always put before xī and běi. Similarly, in the phrase of "zhuō yî", "zhuō" (desk) is put before "yı̌" (chair) because desks are usually taller than chairs, and in "nán nŭ lăo shào" (men and women, old and young), nán (men) and lăo (old) are put before "nǚ" (women) and shào (young) because of the influence of traditional Chinese culture where male and the old are considered superior to female and the young. With the development of human beings and the society, thoughts and ideas like these are recorded faithfully in the language. Conventions play a significant role in the change of language.

\subsection{Psychological Representations of Mental Lexicon}

Both the compositionality and the semantic transparency determine that lexical chunk is a set of lexical items to be holistically stored and retrieved while being used in L2 discourse. The examples in previous part have proved that both the chunk itseself and its components are likely to activate neighboring semantic frames according to the excursive nature of language, and produce neighboring effects as well as a wide range of expressions. Compositionality is the major characteristic of semantic representation of multiword unit. Take "I see" for an example, it is a fixed sentence. It is closure in syntactic structure and word form, used informally with specific meaning "I understand". The later is quite different from "I see". It can be used in both formal and informal situations. The two words in "I understand" are open in structure and word form. For example, "I (You/He/We/They, etc.) undersatand (undersatood/have understood, etc.)" refer to the same meaning. Moreover, it can also be used in the syntactic structure "I understand / I know + object/Clause". Other multiword units like "see you" / "see to it" with the same node word "see" are lexical chunks with relatively stronger compositionality and higher degree of semantic transparency, whose extended semantic meanings are wider than the literal meanings of V + Object phrases like "see a doctor" / "see a film", which is made of up the transitive verb "see" and other noun(s) or pronoun(s). Therefore lexical chunk is the integration of extended meanings of the lexical items in a given context; it is not simply the sum of their basic meanings (Evans, 2009).

Furthermore, a great deal of online processing studies confirm that lexical chunks, an integral part of mental lexicon, owns the advantage of holistic processing with its unique compositional and processing characteristics (Nattinger \& DeCarrico, 2000, p. 12; Jiang \& Nekrasova, 2007, p. 436; Conklin \& Schmitt, 2008, pp. 72-89), and they are the basis for language learners to construct task schema in bilingual lexical processing.

To sum up, we propose that the working definition of lexical chunks is a paired form-meaning word or multiword unit with high compositionality; with rich semantic and pragmatic markers, internal primary ability to produce and process; the external form of the way a native speaker organizes his/her mental lexicon, and has the advantage of holistic processing and representation. 


\section{Attributes of "Formulaic Sequence" and Its Features in Bilingual Processing}

Currently scholars largely premise their studies on "formulaic sequence" with the hypothesis that "formulaic sequence is the basic unit in form-meaning pairing" regardless of the sustentative points about the completeness of its syntactic meaning and lexical meaning. Based on its basic attritutes and processing characteristics, this part argues that "formulaic sequence is the smallest form-meaning entity with clear pragmatic functions, whose constituents (lexical items) form syntagmatic, and paradigmatic or colligation relations between each other according to grammatical rules and communication willingness", and a working definition of formulaic sequence will be discussed.

\subsection{Compositionality and Processing Levels of Formulaic Sequence}

The notion of formulaic sequence, initiated by Cowie, is believed to serve pragmatic functions such as pairing and phrasing; discourse functions with attitudinal nuances. According to Cowie, formulaic sequence can be divided into general and verbal formulaic sequence depending on the communicative situation (quoted from Wei, 2011, p. 22). Some scholars advanced an account that proposes a dual system approach to lexical processing (Sinclair, 1991; Skehan, 1998; Wray, 2000, 2002). They claim that the utterance is made up of two different systems: regularity and memory. The former is an analytical mechanism that entails lexical meanings and grammatical rules to secure language creativeness, while the latter is a formulaic one with default communicative function, and is a necessary requirement for authentic and fluent expression. Currently most of the scholars adopt the definition of formulaic sequence given by Alison Wray, who stressed that this definition is a broad one only for the convenience of research; specific study subject will require restrictive modifiers such as "formulaic word string", "formulaic word and morpheme" (Wray, 2002, p. 9). It follows that formulaic sequence is an ambiguous term that broadly defines the linguistic phenomenon of multiword without telling its similarities and differences with lexical chunks.

In terms of semantic features at syntactic level, formulaic sequence is a semi-open one with lower compositionality compared to lexical chunks, which may be demonstrated by the existence of node words processing and formulaic structure processing in "the inside of the formulaic". From the aspect of node word processing, semi-open compositionality enables more words become node word so that they are given priority for being processed with expected richer semantic contents. From the aspect of formulaic processing, the inherent recursion at syntactic level involves more lexical knowledge and conceptual knowledge, which make the lexical semantic and conceptual structure, and activate lexical productivity (Evans, 2009, 2013). Similar to the way lexical chunks are constructed, lexical items rely on grammatical rules, semantic motivation and cognitive schema to compose formulaic sequence. What's more, their substitutability and excursiveness lend themselves stronger creativeness than lexical chunks, which show more characteristics of "grammaticalized lexis" (Lewis, 1993). Because of the high compositionality and semantic transparency of lexical chunks, the characteristic of lexicalization is more prominent in them.

There are three types of paths to process formulaic sequences, as is shown in the following examples.

Type 1 1a. It be + V-ed (this structure requires the semantic characteristic of the verb be to tell the source of information)

e.g., It is said/reported/estimated, etc.

1b. It be + Adj. (this structure requires the adj express the nature of an event

e.g., It is necessary/important/good/useful, etc.

1c. Subject + think (this structure means the agent is to state his/her points of view

e.g., You/I think/assume/guess;

$\mathrm{He} /$ She thinks /assumes/guesses, etc.

1d. Adv. + Vt-ed (this structure is used only for the collocation of degree adverb and transitive verb

e.g., well-organized / well-done / well-educated / well-dressed

Syntactic and conceptual analysis reveals three common characteristics of the above lexical items:

1). semi-open structure (varied node words and the concurrence lexical items show paradigmatic relations. For example, Structure 1b can activate several different collocation forms like "It be + Adj. + for Sb. to do sth. / It be + Adj. + to do sth. / It be + Adj. + that-clause".

2). distinct lexical semantic structure features (requires node words for specific semantic features. For example, when examples in $1 \mathrm{~d}$ are restricted by the proposition "well", the entire structure denotes positive semantic 
meaning.

3). Obvious pragmatic functions. (For example, 1a is used only to refer to the fact that the information comes from a third party, not including the two speakers in a conversation; $1 \mathrm{c}$ is used to express the ideas of the agent). This type of multiword units is defined as "grammar rules-based formulaic sequence with prominent semantic and pragmatic functions".

Type 2 2a. call off a meeting/look the address up/turn on the light

2b. call it off/look up the address/turn the light on

In the two transitive phrasal verbs above, their allocated objects are allowed to move freely without changing their original meanings. Compared with other types of multiword verbs, they have loose face structures but high degree of compositionality and lexicalization, which means even when the preposition and core verbs are separated, the phrase would keep its original meaning and fixed characteristics of construction (Goldberg, 2006), and are grouped into "transitive phrasal verbs" (Cowan, 2008, p. 175). This type of multiword units is defined as "formulaic sequence with high compositionality, semantic transparency and a freely-shifted object".

Type 3 3a. have it edited / have one's hair cut

3b. make mistake / commit a crime

3c. under discussion / under construction

3d. Love blinds one's eye (Love is blind) / artist's eye vs. London Eye

Examples in 3a have the basic structure of have + Noun / Pron + V-ed, where semantic features (here refers to the passive meaning) are marked by their structures. Similar structures in English like "It takes sb. some time/effort to do sth. / too + Adj. / Adv. + to do / The more...the more" signify specific semantic meanings.

The two verbs of make/commit in $3 \mathrm{c}$ have the same basic but different extended meanings, so they require nouns of different types of meaning (neutral/positive/negative) to be collocated.

The proposition "under" in $3 \mathrm{c}$ refers to the location, which after conceptual metaphor processing, meaning "not finished yet, still in the process of".

The word "eye" in $3 \mathrm{~d}$, after being metaphorically processed, derives from its conceptual meaning the new one"eyesight", which refers to the ability to understand and see the inner nature of things, or to criticize, as is shown in "blind one's eye; artist's eye". While in sentences like "Love blinds one's eye" and the phrase "London Eye", the shift of the attention focus produces new derivative meaning for the word "eye". In the former, the focus is shifted to the word "blind" with negative semantic features, and "blind one's eye" is to express the result of conceptual processing using specific acts, while in the latter, the derivative meaning of "eye" in "London Eye" is a combination of its lexical meaning and conceptual meaning, i.e., "round; overlook; appreciate", thus the name for the wheel of the world famous giant ferry.

This analysis demonstrates that multiword units can be defined as "a formulaic sequence with clear semantic features of node words and image schema, whose specific semantic and pragmatic functions are signified through lexical structures".

In terms of compositionality and semantic transparency, formulaic sequence is weaker than lexical chunks, with the latter enjoying prominent chunk effects, high-degree of lexicalization, and allowing the single word with high lexical semantic load to form a phrase, and the former, a product of the joint efforts of multiword units, demonstrating more prominent characteristics of construction. In terms of lexical semantic structure levels, the latter are the super-ordinate level categories, and may include as its members those lower-level lexical chunks such as compound words, while the former are basic level categories, and don't include any formulaic sequences. In terms of recursion and creativeness, the semi-open structure of the formulaic sequence provides cognitive control mechanism with more opportunities to be involved in processing, which can be seen from the various types of formulaic lexical connections, as well as the fact that the related schema and lexical semantic frame of node words are more easily activated or prohibited. In terms of semantic processing methods, formulaic sequence depends more on the cognitive schema-based conceptual metaphor processing, and is greater in extended semantic meanings and creativeness of the node words. While both formulaic sequence and lexical chunks are the combination of processed and mature lexical semantics, they have the inherent advantage of holistic processing.

To sum up, the working definition of formulaic sequence should be "the grammar rule and semantic motivation-based semi-prefabricated multiword units with high compositionality and semantic transparency, 
who owns semi-open structure, easily-activated node words and rich extended semantic meanings".

\subsection{How Formulaic Sequence and Lexical Chunks Affect L2 Acquisition}

Both SLA and cognitive studies have proved that "lexical chunks" and "formulaic sequence" play a positive role in L2 lexical acquisition and language competency formation, and researchers of bilingual lexical processing generally accept "semantic-based formulaic connections between the words is the basic approach to word processing".

In bilingual context, the prefabricated mechanism in lexical chunks and formulaic sequence enjoys the priority for default function and holistic processing. As stated before, both of them are the lexical semantic combination based on rich motivation and processed conceptually, and are processed up-down. Their high compositionality may effectively help lower the cost of every single word's semantic processing in discourse domain, lessen the burden of memory, and display the advantages of default function and holistic processing more clearly. Meanwhile, the typicality of their structure provides the speaker with a processing sample, which will help them effectively acquire the lexical meanings in a specific discourse domain, grammar rules and processing methods of conceptual meanings, so as to produce chances to create novel language expressions. The processing details are as follows: first the speaker, according his/her communicative goal, activates/prohibits node words, by which accomplishes the processing of the conceptual meaning; then elaborate processing of the semantic meaning starts according to the grammar rules and semantic motivations of the lexical items, so that they are able to fit in discourse domain and meet communication goals, by which accomplished the processing of lexical meaning; at last a discourse with its own style of connections of words is formed and communication goal is achieved. In terms of L2 lexical acquisition, they can help learners acquire the meanings of lexical items as a whole, avoiding ambiguity or misreading because of the existence of polysemy and changed contexts. What's more, their rich motivations are good examples for learners to learn lexical semantic rules and cultural background information of the target language, hence an incidental acquisition of lexical knowledge.

As to the quality of L2 lexical acquisition, the influence of lexical chunks and formulaic sequence could cut different ways. On the one hand, their holistic and cross-leveled way of processing tend to fix speakers' attention on the syntax, semantic, and even discourse, so that a favorable condition could be provided for fluent expression by a fast-completed discourse construction. On the other hand, for medium-lower level of language learners, in language production (especially in speaking and writing), rich semantic markers and redundant information in lexical items could be excessively activated or inhibited, disturbing learner's focus of attention on the lexical level, and consequently affecting the quality of discourse processing. So our suggestion is that when using lexical chunks and formulaic sequence, learners, after they have a good command of their holistic meaning, need reflective study, that is, stress the systematic study of the meaning and rules of every single open word through studying the way its semantic motivation and conceptual meanings are processed. In this way, an all-round lexical knowledge could gradually accumulate.

\section{Conclusion}

For the need of theoretical study and L2 acquisition research, it's necessary to define "lexical chunks" and "formulaic sequence" respectively in a theoretical way. This study concludes that both lexical chunks and formulaic sequence, which share characteristics of psychological representations, are the concrete representations of mental lexicon, and formularized chunks of meanings as result of the interaction between lexical and conceptual meanings, which could effectively help lessen the cognitive burden and possess the advantage of holistic processing due to its characteristic of being formularized and chunked. The main distinctions between the two lie in the degree of semantic compositionality and lexical processing ability. As a multiword unit with comparatively higher semantic compositionality, lexical chunks have fixed compositional methods and components, and specific lexical semantic meaning. Formulaic sequence, on the other hand, has lower degree of compositionality, and it provides "sequence (examples)" instead of "chunks (pre-fabricated materials)" to construct discourse meanings. There is no syntactical or structural change in a formulaic sequence. That is a formulaic sequence keeps conventional word orders and fixed structure. It is evident that Yukuai can't be the substitute of lexical chunks or formulaic sequence. The Yukuai without rigious definition is likely to mislead better understanding of different kinds of multiword in English, and inhibite L2 learner's development in lexical knowledge. We expect SLA researchers to make more efforts on how to develop L2 learner's lexical knowledge in the aspect of lexical processing and the function of lexical chunks and formulaic sequence.

\section{Acknowledgments}

This study was funded by the Zhejiang Province Social Science Project Collocational Links in the L2 Mental Lexicon and Processing in 2012. 


\section{References}

Aichison, J. (1987). Words in the Mind. Oxford: Basil Blackwell.

Aichison, J. (2010). Disasters, devastation and polysemy. The Mental Lexicon, (2), 163-179.

Becker, J. (1975). The Phrasal Lexicon. Cambridge Mass: Bolt and Newman. https://doi.org/10.3115/980190.980212

Bolinger, D. (1976). Meaning and Memory. Forum Linguisticum, (1), 1-14.

Carrol, D. (1999). Psychology of Language. New York: Brooks/Cole Publishing Company.

Carter, R., \& McCarthy, M. (Eds.). (1988). Vocabulary and Language Teaching. London: Longman.

Chapelle, C. A. (1998). Construct definition and validity in SLA research. In L. F. Bachman \& A. D. Cohen (Eds.), Interface between Second language Acquisition and Language Teaching Research. Cambridge: Cambridge University Press.

Collins, A. M., \& Loftus, E. F. (1975). A spreading activation theory of semantic processing. Psychological Review, (82), 407-428. https://doi.org/10.1037/0033-295X.82.6.407

Collins, A. M., \& Quilian, M. R. (1969). Retrieval time from semantic memory. Journal of Verbal Learning and Verbal Behavior, (8), 240-248. https://doi.org/10.1016/S0022-5371(69)80069-1

Conklin, K., \& Schimitt, N. (2008). Formulaic Sequences: Are They Processed More Quickly Than non Formulaic Language by Native and Nonnative Speakers? Applied Linguistics, (29), 72-89.

Cowan, R. (2008). The Teacher's Grammar of English. Cambridge: Cambridge University Press.

Cowie, A. P. (Ed.). (1998). Phraseology: Theory, Analysis, and Application. Oxford: Clarendon Press.

De Bot, K., Lowie, W., \& Verspoor, M. (2005). Second language acquisition: an advanced resource book. New York: Routledge. https://doi.org/10.4324/9780203446416

Dijkstra, A., \& Van Heuven, W. J. B. (2002). The architecture of the bilingual word recognition system: From identification to decision. Bilingualism: Language and Cognition, (5), 175-197. https://doi.org/10.1017/s1366728902003012

Dijkstra, T., \& Van Heuven, W. J. B. (1998). The BIA-model and bilingual word recognition. In J. Grainger \& A. Jacobs (Eds.), Localist connectionist approaches to human cognition. Hillsdale, NJ: Erlbaum.

Dijkstra, T., Miwa, K., Brummelhuis, B., Sappeli, M., \& Baayen, R. H. (2010). How cross-linguistic similarity affects cognate recognition. Journal of Memory and Language, (62), 284. https://doi.org/10.1016/j.jml.2009.12.003

Dong, X. F. (2011). Lexicalization: The Change and Evaluation of Chinese Disyllabic Words. Beijing: Commercial Press.

Evans, V. (2009). How Words Mean. Oxford: Oxford University Press. https://doi.org/10.1093/acprof:oso/9780199234660.001.0001

Evans, V. (2013). Language and Time: A Cognitive Linguistics Approach. Cambridge: Cambridge University Press. https://doi.org/10.1017/CBO9781107340626

Fitzpatrick, T. (2006). Habbits and rabbits: Word Association and the L2 lexicon. In S. Foster-Cohen \& M. Krajnovic (Eds.), EUROSLA Yearbook 6 (pp. 121-145). Amsterdam: John Benjamins.

Foster, P. (2001). Rules \& routines: a consideration of their role in the task-based language production of native and non-native speakers. In M. Bygate, P. Skehan, \& M. Swan (Eds.), Researching pedagogic tasks: Second language learning, teaching, and testing (pp. 75-94). London, New York: Longman.

Goldberg, A. E. (2006). Constructions at Work: The Nature of Generalization in Language. Oxford: Oxford University Press.

Green, D. W. (1998). Mental control of the bilingual lexico-semantic system. Bilingualism: Language and Cognition, (1), 67-81. https://doi.org/10.1017/S1366728998000133

Han, Z. H. (2004). Fossilization in Adult Second Language Acquisition. Clevedon, UK: Multilingual Matters.

Jiang, N. (2004). Conceptual development and thinking in a second language. Modern Foreign Languages, 4, 378-385.

Jiang, N., \& Nekrasova, T. (2007). The processing of formulaic sequences by second language speakers. The 
Modern Language Journal, 91(3), 433-445. https://doi.org/10.1111/j.1540-4781.2007.00589.x

Marslen-Wilson, W. (1987). Functional parallelism in spoken word recognition. Cognition, 25, 71-102. https://doi.org/10.1016/0010-0277(87)90005-9

Marslen-Wilson, W. (1990). Activation, competition, and frequency in lexical access. In G. T. M. Altman (Ed.), Cognitive Models of Speech Processing: Psycholinguistic and Computational Perspectives. Cambridge, MA: MIT Press.

McNeill, D. (1966). A study of word association. Journal of Verbal Learning and Verbal Behavior, 5, 548-557. https://doi.org/10.1016/S0022-5371(66)80090-7

Meara, P. (1996). The dimensions of lexical competence. In G. Brown, K. Malmkjar, \& J. Williams (Eds.), Performance and Competence in Second language Acquisition. Cambridge: Cambridge University Press.

Morten, J. (1982). Disintegrating the lexicon: An information processing approach. In Mehler, Walker, \& Garrett (Eds.), Perspectives on Mental Representation (pp. 89-109).

Namei, S. (2004). Bilingual lexical development: A Persian-Swedish word association study. International Journal of Applied Linguistics, 14, 363-388. https://doi.org/10.1111/j.1473-4192.2004.00070.x

Nation, L. S. P. (1990). Teaching and Learning Vocabulary. New York: Newbury House.

Nattinger, J., \& DeCarrico, J. (2000). Lexical Phrases and Language Teaching. Shanghai: Shanghai Foreign Language Education Press.

Nesselhauf, N. (2005). Collocations in a learner corpus. Amsterdam: John Benjamins. https://doi.org/10.1075/scl.14

Nissen, H., \& Henriksen, B. (2006). Word class influence on word association test results. International Journal of Applied Linguistics, 16, 389-408. https://doi.org/10.1111/j.1473-4192.2006.00124.x

Sinclair, J. M. (1991). Corpus, Concordance, Collocation. Oxford: Oxford University Press.

Skehan, P. A. (1998). Cognitive Approach to Language Learning. Oxford: Oxford University Press.

Tokowicz, N. (2015). Lexical Processing and Second Language Acquisition. New York: Routledge.

Tyler, A. (2012). Cognitive Linguistics and Second Language Learning: Theoretical Basics and Experimental Evidence. NewYork: Routledge.

Wei, N. X. (2011). Fundamentals of Lexis. Shanghai: Shanghai Foreign Language Education Press.

Wolter, B. (2001). Comapring the L1 and L2 mental lexicon: A depth of individual word knowledge model. Studies in Second Language Acquisition, 23, 41-69. https://doi.org/10.1017/S0272263101001024

Wray, A. (2002). Formulaic Language and the Lexicon. Cambridge: Cambridge University Press. https://doi.org/10.1017/CBO9780511519772

Zareva, A. (2005). Models of L2 learners' vocabulary knowledge assessment. System, 33, 547-562. https://doi.org/10.1016/j.system.2005.03.005

Zhao, Y. (2011). Fossilization in the Output of High-frequency Words from the "Noticing" Perspective. Foreign Language Research, 3, 100-103.

\section{Notes}

Note 1. According to Alison Wray (2002, p. 9), there appeared as many as 57 special terms to refer to a cluster of words. To avoid ambiguity, "multi-word unit" is adopted in this article in this matter.

Note 2. According to CKNI data, the word "yukuai" made its earliest appearance in An Overview of Shallow Syntax Analysis Method (Sun Honglin, Yu Shiwen, Contemporary Linguisticts, 2000(2), pp. 74-83). In this article, Yukuai is defined as "non-recursive noun phrases, verbal phrases, etc.", and thus the proposal that "yukuai and phrase are interchangeable". In 2004, Yao Baoliang, in his article Prefabricated Lexical Chunk and Oral English Teaching in Middle school, put forward the term of "Yuzhi Yukuai" (translated as "prefabricated lexical chunk", generally referring to a string of language structure), in which Yukuai has the closest meaning to the current one (Curriculum, Textbook and Methodology, pp. 33-38, 2004(4)). Then the word "yukuai" was first used at the conference of the First National Symposium on Formulaic Language Teaching and Research in 2009, University of International Business and Economics. From 2001-2015 (except 2002, 2003), the annual number of articles published on Yukuai is 1,2,3,2,3,12,13,15,28,24,19,15,10, in which less than 10 articles discussed the definition and nature of yukuai in L1 or L2 learning. 


\section{Copyrights}

Copyright for this article is retained by the author, with first publication rights granted to the journal.

This is an open-access article distributed under the terms and conditions of the Creative Commons Attribution license (http://creativecommons.org/licenses/by/4.0/). 